\title{
Effect of manually applied device on hand strength and functions in physiotherapists
}

\author{
Rana Hussein MOHAMED, Wadida H. ELSAYED, and Doaa Ibrahim AMIN \\ Basic Science Department, Faculty of Physical Therapy, Cairo University, Egypt \\ Corresponding author's Email: Rana.h1912@gmail.com.; (iD) ORCiD: 0000-0001-5188-6700
}

\section{ABSTRACT}

Introduction. Musculoskeletal injuries are one of the largest health problems among physiotherapists, because their work exposes them to have a high risk of grip strength, pinch of thumb strength, and hand functions problems. Aim. This study aimed to investigate the effect of the manually applied cavitation device on hand grip, pinch of thumb strength, and hand functions. Methods. From 60 physiotherapists were participated in this research, 30 of them (as group A with 30 subjects) did not use the manually applied cavitation device before and 30 physiotherapists (as group B with 30 subjects) used the manually applied cavitation device at least for one year. Handheld dynamometer has been used to measure grip strength, pinch dynamometer was used to measure pinch of thumb strength, and Michigan questionnaire was used to assess hand functions. Results. In group A (within group) there was no significant difference of pinch strength or hand functions when compared between dominant hand and non-dominant hand of the same subject, while there was significant increase of grip strength at dominant side compared to non-dominant side. In group B (within group) there was no significant difference of grip strength and hand functions when compared between dominant hand and non-dominant hand of the same subject while there was significant increase of pinch strength at dominant side compared to non-dominant side. A comparison between dominant sides of groups $A$ and $B$, and also between non-dominant sides groups A and B showed significant increase of pinch of thumb strength of dominant and nondominant side of group $A$ in relation to group $B$. There was significant increase of hand functions of dominant side of group $A$ in relation to group $B$ while there was no significant difference of hand functions of non-dominant side between groups A and B. Conclusion. Workrelated wrist-hand grip strength, pinch of thumb strength, and hand functions in physiotherapists is a prevalent problem among physiotherapists who perform manual techniques and use manually applied device for long time. Recommendation. Similar studies should be done on large group, and also for physiotherapists working for many years with the manually applied cavitation device; there is a need to find the effect of the manually applied cavitation device on elbow, shoulder, and cervical pain in physiotherapists.

\section{Original Article}

PII: S225199392100009-11

Rec. 17 April 2021

Rev. 21 July 2021

Acc. 25 July 2021

\section{Keywords}

Work-related musculoskeletal disorder, Manually applied device,

Physiotherapists,

Hand functions

\section{INTRODUCTION}

Work-related musculoskeletal disorder (WRMD) known as a type of musculoskeletal injury that is common between physiotherapists [1], results from a work-related event, work restriction, lost work time or search for another job. The nature of the work between physiotherapists is physically demanding, and it involves repetitive tasks, high-force manual techniques for treating patients, techniques that exert direct pressure on certain joints during treatment, awkward positioning of joints during certain techniques and prolonged postures [2].

The injuries differ between junior and senior physiotherapists. The incidence of work injuries is the highest within the first 5 years of practice, and it is more common in junior physiotherapists and newly qualified graduates [3]. The job risk factors of most concern were sustained posture, manual therapy techniques, repetition, working while injured and excessive workloads. Hand-injured physiotherapists are most common in using manual therapy techniques and repetition specially injuries to base of thumb and wrist [4]. The thumb pain and hand-wrist has become a recognized problem for physiotherapists who apply manual maneuvers [4] and affects the physiotherapist ability to apply manual treatments as it influences strength and function of hand-wrist and thumb [5]. 
The Cavitation which is a new technique for fat lipolysis that appears in the last few years is considered as a device that is applied manually by its big and heavy head for a long period of time (at least 35 minutes) and its application cause the work-related hand-wrist and thumb of pain, grip strength, pinch of thumb strength, and hand function problems. Also, the ultrasound head is small and applied for a short period of time that did not cause any hand wrist problems except after working for a prolonged time over years which is not a common problem among physiotherapist (it is proved by a field study done on Egyptian physiotherapists) [6]. The handheld dynamometer is used to measure grip strength and the pinch dynamometer is used to measure pinch strength [7]. Michigan hand outcomes questionnaire which is valid and reliable is used to assess hand function [8].

There were few studies about the effect of the manually applied devices on wrist/hand grip strength, pinch of thumb strength and hand functions among physiotherapists, hence this study aimed to investigate the effect of the manually applied devices on wrist/hand grip strength, pinch of thumb strength and hand functions.

\section{MATERIALS AND METHODS}

The current study conducted at different out clinics of different hospitals (Air Force Specialized hospital and New Cairo hospital) in Cairo, Egypt and in the out clinic of faculty of physiotherapy Cairo university in Egypt from 2016 to 2018 to physiotherapists with the age group of 20-30 years to investigate the effect of the manually applied cavitation device on hand-wrist grip strength and pinch of thumb strength and hand functions. This work was a cross-sectional observational study conducted on 60 physiotherapists (male and female), divided in two groups. Thirty physiotherapists that did not use the manually applied cavitation device before and 30 physiotherapists those used the manually applied cavitation device at least for one year.

\section{Ethical approval}

All physiotherapists in the study after signing an institutionally approved informed consent (appendix 1) and after approval of ethical commit of faculty of physical therapy, Cairo University with No: P.T.REC/012/003226.

\section{Instrumentation}

\section{The handheld dynamometer (HHD)}

Handheld dynamometer is small and portable, and measure strength objectively in kilograms. The subject holds the dynamometer with shoulder adducted and neutrally rotated, elbow flexed 90 degrees, forearm neutral and wrist held between 0-15 degrees of ulnar deviation. The therapist stabilizes the limb segment (arm and forearm) while encouraging the patient to exert as much force against the device as possible and the maximum force is recorded by the HHD and repeat 3 times. Such devices have been proven to have well to excellent reliability and validity in different populations [9].

\section{The pinch dynamometer}

It is a valid and reliable device used to measure pinch of thumb strength in kilograms. Measurement was achieved by pressing the front part of the thumb together with the side part of the index finger in the standard position, subjects were seated in a chair, with their shoulders adducted and neutrally rotated, and their elbows flexed 90 degrees, their forearms positioned neutrally, and their wrists flexed in 0-30 degrees and 0-15 degrees of ulnar deviation [10].

\section{Michigan questionnaire}

The Michigan Hand Outcomes Questionnaire is valid and reliable. It is a tool used to assess patients with hand disorders through the measurement of 6 health domains: overall hand function, activities of daily living (ADLs), pain, work performance, aesthetics, and patient satisfaction [8].

\section{Procedure}

The measurement took place in a quiet room to avoid any distraction. First, the aim of the study and the procedure has been explained to each therapist. Second, the therapist signed the patient concept and agreement of ethical committee No: P.T.REC/012/003226 approved by faculty of physical therapy, Cairo University. Third, each therapist subjected to the measurement of grip strength by the handheld dynamometer, pinch of thumb strength by pinch dynamometer and hand functions by filling the Michigan questionnaire. 


\section{Data collection}

The data was collected through A) personal sheet: age in years, sex (male or female), height in $\mathrm{cm}$, and weight in kg; B) grip strength: measured in $\mathrm{kg} ; \mathrm{C}$ ) pinch strength: measured in kg; D) hand functions: Michigan questionnaire.

\section{Statistical analysis}

The gathered data was calculated and analyzed in the following methods:

a. Mean, standard deviation SD (MANOVA) for the parametric normally distributed data (age, height, weight, BMI, pinch strength, hand function). 1) Paired t test conducted within groups (comparison between dominant hand and non-dominant hand of the same subject in groups A and B); 2) Independent t-test conducted between groups (comparison between dominant sides of groups $A$ and $B$ ), then comparison between nondominant sides of groups A and B).

b. Median and Quartile range for the non-parametric (grip strength). 1) Wilcoxon signed rank test used within groups (comparison between dominant hand and non-dominant hand of the same subject in both groups $A$ and B); 2) Mann-Whitney $U$ test used between groups (comparison between dominant sides of groups $A$ and B), and comparison between non-dominant sides of groups A and B).

\section{RESULTS}

\section{Subjects' characteristics}

The current study was conducted on 60 physiotherapists; 30 of them did not use the manually applied cavitation device before and 30 physiotherapists use the manually applied cavitation device at least for one year. Group A was included of 30 subjects with mean age, body mass, height, and BMI values of $26.7 \pm 3.3$ years, $74.46 \pm 12.81 \mathrm{~kg}, 169.53 \pm 7.26 \mathrm{~cm}$, and $25.91 \pm 3.67 \mathrm{Kg} / \mathrm{m}^{2}$, respectively and group B was included of 30 subjects with mean age, body mass, height, and BMI values of $26 \pm 2.9$ years, $72.66 \pm 13.49 \mathrm{~kg}, 169.26 \pm 8.87 \mathrm{~cm}$, and $25.52 \pm 3.44$ $\mathrm{Kg} / \mathrm{m}^{2}$, respectively. As indicated by the independent $t$ test, there were no significant differences (p>0.05) in the mean values of age, body mass, and height between both tested groups (Table 1). The sex distribution of group A revealed that there were 17 females with reported percentage of $56.6 \%$ and 13 males with reported percentage of 43.4\%. The sex distribution of group B revealed that there were 15 females with reported percentage of $50 \%$ and 15 males with reported percentage of 50\% (Table 1). Chi square revealed no significant differences between both groups in sex distribution ( $\mathrm{p}>0.05)$.

\section{A) Parametric normally distributed tests (2×2 mixed design MANOVA)}

1) Overall effect: Statistical analysis using $2 \times 2$ mixed design MANOVA indicated that there were significant effects between group to compare between dominant sides of groups A and B then between non-dominant side of groups A and B (the first independent variable) on all tested dependent variables; (pinch strength and function scale) ( $\mathrm{F}=7.67, \mathrm{P}=0.001)$. However, there were significant effects within group to compare between dominant hand and non-dominant hand of same subject in groups $A$ and $B$ (the second independent variable) on the tested dependent variables; (pinch strength and function scale) $(\mathrm{F}=0.715, \mathrm{P}=0.491)$. However, the interaction between the two independent variables was significant, which indicates that the effect of between subjects (first independent variable) on the dependent variables was influenced by within subjects (second independent variable) ( $\mathrm{F}=1.19, \mathrm{P}=0.306)$ (Table 2).

\section{2) Multiple pairwise comparison tests (Post hoc tests) \\ Pinch strength}

a) Within groups. As presented in table (3) within group's comparison the mean \pm SD values of Pinch strength in the dominant side and non-dominant side were $18.8 \pm 5.07$ and $17.8 \pm 4.37$ respectively in the group (A). Multiple pairwise comparison tests (Post hoc tests) revealed that there was no significant difference of Pinch strength at dominant side in compared to non-dominant side (P-value $=0.391$ ). While the mean $\pm \mathrm{SD}$ values of Pinch strength in the dominant and non-dominant sides were $16.03 \pm 3.7$ and $15.27 \pm 4.1$ respectively in the group (B). Multiple pairwise comparison tests (Post hoc tests) revealed that there was no significant difference of Pinch strength at dominant side in compared to non-dominant side (P-value =0.496).

b) Between groups. Considering the effect of between group (first independent variable) on Pinch strength, Multiple pairwise comparison tests (Post hoc tests) revealed that the mean values of the dominant side between both groups showed significant differences with $(\mathrm{P}$-value $=0.015)$ and this significant increase in 
favor to group (A) in compared to group (B). While, multiple pairwise comparison tests (Post hoc tests) revealed that there was significant difference of the mean values of the non-dominant sides between both groups with (P-value=0.024) this significant increase in favor to group $(\mathrm{A})$ compared to group $(\mathrm{B})$.

\section{Functional scale}

a) Within groups: As presented in table (4) within group's comparison the mean \pm SD values of Functional scale in dominant and non-dominant sides were77.2 \pm 5.88 and $75.7 \pm 7.1$, respectively in group (A). Multiple pairwise comparison tests (Post hoc tests) revealed that there was no significant difference of Functional scale at non-dominant side in compared to dominant side (P-value $=0.444)$. While the mean $\pm \mathrm{SD}$ values of Functional scale in dominant and non-dominant sides were71.9 \pm 9.06 and $74.8 \pm 8.9$ respectively in the group (B). Multiple pairwise comparison tests (Post hoc tests) revealed that there was no significant difference of Functional scale at dominant side in compared to non-dominant (P-value $=0.156)$.

b) Between groups: Considering the effect of the tested group (first independent variable) on Functional scale, Multiple pairwise comparison tests (Post hoc tests) revealed that the mean values of dominant side between both groups showed significant differences with ( $\mathrm{P}$-value=0.010*) and this significant increase in favor to group (A) in compared to group (B). While, multiple pairwise comparison tests (Post hoc tests) revealed that there was no significant difference of the mean values of non-dominant side between both groups with ( $p$ value $=0.673$ )

\section{B) Non-parametric tests}

\section{Grip strength}

a) Within groups. Table 6 show median score, U, Z and P-values of the grip strength at dominant and nondominant sides in both groups. In group $A$, the median score Interquartile range (IQR) of grip strength in the dominant and non-dominant sides were 35.5(21.7-50) and 34(20-50) respectively. Wilcoxon Signed Rank tests revealed that there was significant increase in grip strength at dominant side in compared to non-dominant side $\left(Z\right.$-value $=-3.109$, $P$-value $\left.=0.002^{*}\right)$. While in group $B$, the median score $(\mathrm{IQR})$ of grip strength in the dominant and non-dominant sides were 25(20-45.7) and 24.5(20-44.2) respectively. Wilcoxon Signed Rank tests revealed that there was no significant difference in grip strength at dominant side in compared to nondominant side (Z-value $=-1.087$, P-value $=0.281)$.

b) Between groups. Considering the effect of between group (first independent variable) on the grip strength, Mann-Whitney tests revealed there was no significant difference between both groups dominant side $(\mathrm{U}$-value $=344, \mathrm{Z}$-value $=-1.566$, and $\mathrm{P}$-value $=0.117)$. In addition, Mann-Whitney tests revealed that there was no significant difference of the median values of the non-dominant side between both groups with (U-value = 370, Z-value $=-1.185$, and $\mathrm{P}$-value= 0.236).

Table 1. Physical characteristics of patients in both groups ( $A$ and $B$ )

\begin{tabular}{lccccc}
\hline \multirow{2}{*}{ Items } & Group A & Group B & \multicolumn{2}{c}{ Comparison } \\
\cline { 2 - 5 } & Mean \pm SD & Mean \pm SD & t-value & P-value \\
\hline Age (years) & $26.7 \pm 3.3$ & $26 \pm 2.9$ & 0.788 & 0.434 & NS \\
Body mass (Kg) & $74.46 \pm 12.81$ & $72.66 \pm 13.49$ & 0.53 & 0.598 & NS \\
Height $(\mathrm{cm})$ & $169.53 \pm 7.26$ & $169.26 \pm 8.87$ & 0.127 & 0.899 & NS \\
BMI $\left(\mathrm{kg} / \mathrm{m}^{2}\right)$ & $25.91 \pm 3.67$ & $25.52 \pm 3.44$ & 0.424 & 0.673 & NS \\
\hline Sex distribution N (\%) & Group A & Group B & $\mathbf{X}^{\mathbf{2}}$ & P-value \\
Female & $17(56.6 \%)$ & $15(50 \%)$ & \multirow{2}{*}{0.268} & 0.605 & NS \\
Male & $13(43.4 \%)$ & $15(50 \%)$ & & & \\
\hline
\end{tabular}

SD: standard deviation, P: probability, S: significance, NS: non-significant.

Table 2. The $2 \times 2$ mixed design Multivariate Analysis of Variance (MANOVA) for pinch strength and function scale between both groups

\begin{tabular}{lcc}
\hline Source of Variation & F-value & P-value \\
\hline Between subjects & 7.67 & 0.001 \\
Within subjects & 0.715 & 0.491 \\
Interaction & 1.19 & 0.306 \\
\hline
\end{tabular}

Significant level is set at alpha level $<0.05$. 
Table 3. Mean \pm SD and $p$ values of Pinch strength at both involved sides at both groups

\begin{tabular}{|c|c|c|c|c|}
\hline \multirow{2}{*}{ Pinch strength } & Dominant side & Non-dominant side & \multirow{2}{*}{ MD } & \multirow{2}{*}{ p-value } \\
\hline & Mean \pm SD & Mean \pm SD & & \\
\hline Group A & $18.8 \pm 5.07$ & $17.8 \pm 4.37$ & 1 & 0.391 \\
\hline Group B & $16.03 \pm 3.7$ & $15.27 \pm 4.1$ & 0.76 & 0.496 \\
\hline MD & 2.7 & 2.53 & & \\
\hline $\mathrm{p}$-value & $0.015^{*}$ & 0.024 & & \\
\hline
\end{tabular}

Significant level is set at alpha level <0.05, SD: standard deviation. MD: Mean difference, p-value: probability value

Table 4. Mean $\pm S D$ and $p$ values of Functional scale at both involved sides at both groups

\begin{tabular}{lcccc}
\hline \multirow{2}{*}{ Functional scale } & Dominant side & Non-dominant side & MD & p-value \\
\cline { 2 - 3 } & Mean \pm SD & Mean \pm SD & $75.7 \pm 7.1$ & 1.5 \\
\hline Group A & $77.2 \pm 5.88$ & $74.8 \pm 8.9$ & -2.9 & 0.444 \\
Group B & $71.9 \pm 9.06$ & 0.9 & \\
MD & 5.3 & 0.673 & \\
p- value & $0.010^{*}$ & & \\
\hline
\end{tabular}

Significant level is set at alpha level <0.05, SD: standard deviation. MD: Mean difference, p-value: probability value.

Table 6. Median, $U, Z$, and p values of grip strength at both involved sides at both groups

\begin{tabular}{|c|c|c|c|c|}
\hline \multirow{2}{*}{ Grip strength } & Dominant side & Non dominant side & \multirow{2}{*}{ Z-value } & \multirow{2}{*}{ p-value } \\
\hline & Median (IQR) & Median (IQR) & & \\
\hline Group A & $35.5(21.7-50)$ & $34(20-50)$ & -3.109 & $0.002 *$ \\
\hline Group B & $25(20-45.7)$ & $24.5(20-44.2)$ & -1.087 & 0.281 \\
\hline U-value & 344 & 370 & & \\
\hline Z-value & -1.566 & -1.185 & & \\
\hline $\mathrm{p}$-value & 0.117 & 0.236 & & \\
\hline
\end{tabular}

Significant level is set at alpha level <0.05, IQR: interquartile range, $\mathrm{p}$-value probability value.

\section{DISCUSSION}

The objective of the current study was to investigate the effect of the manually applied cavitation device on grip strength, pinch of thumb strength and hand functions among physiotherapists at different out clinics of different hospitals (Air Force Specialized hospital and New Cairo hospital) in Cairo, Egypt and in the out clinic of faculty of physiotherapy Cairo University in Egypt.

Musculoskeletal injuries are one of the largest health problems between physiotherapists, because of their work expose them to have a high risk of pain, The nature of the work is physically demanding, and it involves repetitive tasks, high-force manual techniques for treating patients, maneuvers that exert direct pressure on certain joints during treatment, awkward positioning of joints during certain techniques and prolonged postures, this current study was conducted for that purpose.

In the current study, the pinch strength within groups (comparison between dominant hand and nondominant hand of the same subject in both groups $A$ and B) in group (A) there was no significant difference of pinch strength at dominant side compared to non-dominant side, in group (B) there was significant increase of pinch strength at dominant side compared to non-dominant side. The pinch strength between groups (compare between dominant side of group (A) and dominant side of group (B), then compare between non-dominant side of group (A) and non-dominant side of group (B)) there was significant difference of dominant side and this significant increase in favor to group (A) compared to group (B). While there was significant difference of nondominant side between both groups this significant increase in favor to group (A) compared to group (B).

In the current study, the functional scale within groups (Comparison between dominant hand and nondominant hand of the same subject in group $A$ and $B$ ) in group (A) there was no significant difference of hand functions at dominant side compared to non-dominant side, in group (B) there was no significant difference of hand functions at dominant side compared to non-dominant side. But the functional scale between groups (compare between dominant side of group (A) and dominant side of group (B), then compare between non dominant side of group (A) and non-dominant side of group (B)), there was significant difference of the dominant side between both groups and this significant increase in favor to group (A) in compared to group (B), while there was no significant difference of the non-dominant side between both groups. 
In this study the grip strength within groups (comparison between dominant hand and non-dominant hand of the same subject in group A and B), there was significant increase in grip strength at dominant side compared to non-dominant side. While in group (B) there was no significant difference in grip strength at dominant side compared to non-dominant side. And the grip strength between groups (compare between dominant side of group (A) and dominant side of group (B), then compare between non dominant side of group (A) and non-dominant side of group (B)) there was no significant difference between both groups in dominant side and non-dominant side.

Useh et al. [11] said that the symptoms of hand, thumb, and wrist injury sustained at work were also a dilemma for over two-thirds of the therapists reporting work-related musculoskeletal disorders. Physiotherapists who reported performing manual therapy on a routine basis were 2.5 times more likely to experience these indications than those who did not show performing these procedures. Furthermore, this supports our findings which have associated manual therapy techniques with thumb, wrist, and hand workrelated musculoskeletal disorders. As a result, manual therapy approaches appear to be a significant contributor to upper limb musculoskeletal stress.

Trying to estimate the amount of time to perform manual techniques, although increased time spent performing manual techniques has been previously reported to increase the prevalence of work-related hand pain in physiotherapists [3]. In the survey by Cromie et al. [3], the greatest difference in prevalence was between those who performed manual techniques from 1 to 5 hours per week (about 25\% prevalence) and 6 to 10 hours per week (over 50\% prevalence), with the prevalence reaching a plateau of about 60\% as hours spent performing manual techniques increased. In the present study, participants reported they performed manual techniques at least 10 hours per week, so both groups were perhaps performing manual techniques above a threshold of hours per week and this increased risk of hand pain.

Severity of symptoms was related to the hours spent performing manual techniques per week. Therapists who spent more time doing the same task of manual application repeatedly had more severe hand symptoms. Concepts such as job rotations, allow breaks in repetitive activities and variety in work are commonly done to avoid overloading to any anatomical area, either by sustained posture or repetitive actions as they are risk factors in the development of cumulative trauma disorders [3].

A previous study has shown that musculoskeletal problems are common in health care workers who are in direct contact with patients [12], and other studies have said that physical therapists have a high prevalence of occupational injuries compared to other health workers [13]. The current study found that most of the physical therapists experienced work-related musculoskeletal disorder and our findings agree with the study by Salik and Özcan [1] in Turkey reported a high prevalence of work-related injuries among physical therapists, also reported repeated movement and working when physically fatigued as causative factors. These results also supported by Cromie et al. [3] who said that the lifetime prevalence of work-related MSDs among physical therapists was high.

Wrist and hand are the most common regions involved in musculoskeletal disorders in this study. This work is supported by West and Gardner [4] reported that 25\% of the physical therapists had experienced a hand injury during work. The work-related activities that most commonly cause injuries among physical therapists was performing manual therapy techniques. Also working on injured joint and performing manual therapy techniques lead to more injuries.

According to the independent samples t-test, the mean variables of body mass, height, and age between the two groups in this study with a $\mathrm{p}$-value greater than 0.05 were statistically non-significant. These results disagree with many studies have been done to evaluate the relationship between muscle strength and BMI. Some of these studies have shown a direct and positive relation between these two parameters. [14, 15] and another study found inverse relationship between muscle strength and BMI.

Klum et al. [16] has reported a positive relation between BMI with grip and pinch strength but they found an inverse relation between age with grip and pinch strength. Yasuo et al. [14] also found a significant relation between maximum grip strength in dominant hand and common anthropometric variables in all studied age groups. Previous studies [17] have established that there is a relationship between hand strength and age. These developed normative data based on a linear inverse relationship; the maximal hand strength is decreased with increasing age. Alahmari et al. [18] showed that BMI was significantly correlated $(\mathrm{P}<0.05)$ with hand grip strength in both boys and girls.

In the current study pinch strength between groups revealed that the mean values of the dominant side and the non-dominant side between both groups showed significant differences and this significant increase in 
favor to group A in compared to group B. This result disagrees with the study by Lau and Ip [19] who reported that the mean dominant lateral pinch strengths between non-manual and manual workers showed no significant difference in both groups. But the result agrees with the results observed by Josty et al. [20], who found significant differences in both the dominant lateral pinch strength between non-manual and manual workers.

Our study revealed that there was significant increase of pinch strength at dominant side compared to non-dominant side, this agrees with the previous study observed by Lau and Ip [19] who found that lateral pinch strengths are significantly different between hands within each group of subjects. Also, El-Gohary et al. [21] reported that the pinch strength of the non-dominant side was significantly less than that on the dominant side.

Our results in the current study revealed that there was significant difference in grip strength at dominant side in compare to non-dominant side in group A. This is agreed with Habibi et al. [22] who reported that grip strength for the dominance hand was significantly higher than non-dominant hand for all workloads. Also, it is agreed with Adedoyin et al. [23] who said that the dominant hand was significantly stronger than the non-dominant hand without sex bias.

Grip strength in this current study revealed that there was no significant difference between both groups in dominant side and the non-dominant side. And this is agreed with Lau and Ip [19] who reported that grip strengths of the dominant side was compared between non-manual and manual workers and no statistically significant difference was demonstrated between these two groups for power grip.

Our findings are agreeing with many studies that showed that there is a significant difference between grip strength of dominant hand and non-dominant hand [24]. Also, studies agreed with our results in group (A) within group have showed grip strength for dominant hand was higher than non-dominant hand [25]. Alahmari et al. [18] showed that the dominant hand can generate more hand grip strength than the non-dominant hand.

In this study, the functional scale within group revealed that there was no significant difference of functional scale between dominant and non-dominant sides. This is disagreeing with Özcan et al. [26] who reported that the manual function is less pronounced in left-handed people than in right-handed people. This is agreed with our results of the functional scale between groups revealed that there were significant differences on the mean values of the dominant side between both groups and this significant increase in favor to group $A$ in compared to group B. There was no significant difference of the mean values of the non-dominant side between both groups. Choi et al. [27] said that there is a decrease in hand function based on aging was more significant in females than males. This contradicted to our result of the current study that indicated by the independent $t$ test, there were no significant differences $(p>0.05)$ in the mean values of age.

\section{CONCLUSION}

Work-related wrist/hand grip strength, pinch of thumb strength, and hand functions in physiotherapists continues to be a prevalent problem among physiotherapists who administer manual techniques and use manually applied device for long time. Factors that appear to be associated with problems include muscle elasticity and strength. The most common work-related injury was hand pain, decrease pinch strength and hand functions with perceived exacerbation of symptoms caused through prolonged use of manually applied devices, manual techniques as mobilization, awkward postures, lifting, repetitive movement and handling. It is important for physiotherapists to be aware of these risk factors and limitations associated with their profession so they can take steps to prevent these painful and disabling conditions. Postural risk factors, the performance of manual hand techniques, and workload issues were related to symptoms in the wrists, hands, and thumbs. As has been demonstrated by other researchers, knowledge of ergonomics, injury, and treatment does not offer the physical therapist immunity from injury. Further research is needed to identify those aspects of the job and associated work practices contributing to injury, with a view to formulating preventive strategies.

\section{Limitations}

Major limitations of this study were, first that the participants were recruited from a single university, which may affect generalizability of our results to the whole Egyptian population. The second point is that although the inclusion and exclusion criteria facilitate selection of subjects from the target populations, recruitment of patients who suffered from medical conditions not involving the cervical spine and the upper extremities as grip test subjects could still be arguable. The third point is that lack of computation of the hobby 
habits in the data analysis invariably limited the scope of explanation of grip strength performance between participants.

\section{DECLARATIONS}

\section{Authors' Contributions}

All authors contributed equally to this work. Or

\section{Competing interests}

The authors declare that they have no competing interests.

\section{REFERENCES}

1. Salik Y, Özcan A. Work-related musculoskeletal disorders: a survey of physical therapists in Izmir-Turkey. BMC musculoskeletal disorders. 2004 Dec;5(1):1-7. https://doi.org/10.1186/1471-2474-5-27

2. Nordin NA, Leonard JH, Thye NC. Work-related injuries among physiotherapists in public hospitals: a Southeast Asian picture. Clinics. 2011; 66:373-8. https://doi.org/10.1590/S1807-59322011000300002

3. Cromie JE, Robertson VJ, Best MO. Work-related musculoskeletal disorders in physical therapists: prevalence, severity, risks, and responses. Physical therapy. 2000 Apr 1;80(4):336-51. https://doi.org/10.1093/ptj/80.4.336

4. West DJ, Gardner D. Occupational injuries of physiotherapists in North and Central Queensland. Australian Journal of physiotherapy. 2001 Jan 1;47(3):179-86. https://doi.org/10.1016/S0004-9514(14)60265-8

5. Snodgrass SJ, Rivett DA, Chiarelli P, Bates AM, Rowe LJ. Factors related to thumb pain in physiotherapists. Australian Journal of Physiotherapy. 2003 Jan 1;49(4):243-50. https://doi.org/10.1016/S0004-9514(14)60140-9

6. Abd El-Hamed MY, El-Gendy MH and Abd El Rahman EM. Influence of Ultrasound Cavitation and Electro-lipolysis on obesity management. In Journal of American Science. 2014; 10(9): 188-196. Link

7. Kim JS, Lee SG, Park SK, Lee SM, Kim BK, Choi JH, Kim SH. Comparison of grip and pinch strength between dominant and nondominant hand according to type of handedness of female college students. Journal of International Academy of Physical Therapy Research. 2011;2(1):201-6. https://doi.org/10.5854/JIAPTR.2011.2.1.201

8. Chung KC, Pillsbury MS, Walters MR, Hayward RA. Reliability and validity testing of the Michigan Hand Outcomes Questionnaire. The Journal of hand surgery. $1998 \mathrm{Jul}$ 1;23(4):575-87. https://doi.org/10.1016/S0363-5023(98)80042-7

9. Le-Ngoc L, Janssen J. Validity and reliability of a hand-held dynamometer for dynamic muscle strength assessment. Rehabil Med. 2012 Jul 19;4: 53-66. Google Scholar

10. Shin H, Moon SW, Kim GS, Park JD, Kim JH, Jung MJ, Yoon CH, Lee ES, Oh MK. Reliability of the pinch strength with digitalized pinch dynamometer. Annals of Rehabilitation Medicine. 2012 Jun; 36(3):394-399. DOI: https://dx.doi.org/10.5535\%2Farm.2012.36.3.394

11. Useh U, Igumbor EU, Madzivire DM. Occupational injuries among physiotherapists: a case study in Zimbabwe: original contribution. African Safety Promotion. 2003 Dec 1;1(2):26-33. https://hdl.handle.net/10520/EJC92962

12. Akinbo SRA. Injuries on the Job: Physiotherapists (PTs) at risk (editorial). Nigerian Journal of Medical Rehabilitation, $2006,11: 119$.

13. Rugelj D. Low back pain and other work-related musculoskeletal problems among physiotherapists. Applied ergonomics. 2003 Nov 1 ; 34(6):635-9. https://doi.org/10.1016/S0003-6870(03)00059-0

14. Yasuo G, Daisaku T, Nariyuki M, Jun'ya S, Toshihiko O, Masahiko M, Yoshiyuki M. Relationship between grip strength and surgical results in rotator cuff tears. Shoulder joint. 2005; 29(3): 559-62. Google Scholar

15. Kellor M. Hand strength and dexterity. American Journal of Occupational Therapy. 1971; 25:77-83. https://ci.nii.ac.jp/naid/10016308535/

16. Klum $M$, Wolf MB, Hahn P, Leclère FM, Bruckner $T$, Unglaub F. Predicting grip strength and key pinch using anthropometric data, DASH questionnaire and wrist range of motion. Archives of orthopaedic and trauma surgery. 2012 Dec;132(12):1807-11. https://doi.org/10.1007/s00402-012-1602-8

17. Pedersen AN, Ovesen L, Schroll M, Avlund K, Era P. Body composition of 80-years old men and women and its relation to muscle strength, physical activity and functional ability. The Journal of nutrition, health \& aging. 2002 Jan 1;6(6):413-20. Google Scholar

18. Alahmari KA, Kakaraparthi VN, Reddy RS, Silvian PS, Ahmad I, Rengaramanujam K. Percentage difference of hand dimensions and their correlation with hand grip and pinch strength among schoolchildren in Saudi Arabia. Nigerian journal of clinical practice. 2019 Oct 1; 22(10):1356. https://doi.org/10.4103/njcp.njcp_121_19

19. Lau VW, Ip WY. Comparison of power grip and lateral pinch strengths between the dominant and non-dominant hands for normal Chinese male subjects of different occupational demand. Hong Kong Physiotherapy Journal. 2006 Jan 1;24(1):16-22. https://doi.org/10.1016/S1013-7025(07)70004-O

20. Josty IC, Tyler MP, Shewell PC, Roberts AH. Grip and pinch strength variations in different types of workers. Journal of Hand Surgery. 1997 Apr; 22(2):266-9. https://doi.org/10.1016/S0266-7681(97)80079-4

21. El-Gohary TM, Abd Elkader SM, Al-Shenqiti AM, Ibrahim MI. Assessment of hand-grip and key-pinch strength at three arm positions among healthy college students: dominant versus non-dominant hand. Journal of Taibah University Medical Sciences. 2019 Dec 1; 14(6):566-71. https://doi.org/10.1016/j.jtumed.2019.10.001

22. Habibi E, Kazemi M, Dehghan H, Mahaki B, Hassanzadeh A. Hand grip and pinch strength: Effects of workload, hand dominance, age, and body mass index. Google Scholar 
23. Adedoyin RA, Ogundapo FA, Mbada CE, Adekanla BA, Johnson OE, Onigbinde TA, Emechete AA. Reference values for handgrip strength among healthy adults in Nigeria. Hong Kong Physiotherapy Journal. 2009 Jan 1;27(1):21-9. https://doi.org/10.1016/S10137025(10)70005-1

24. Incel NA, Ceceli E, Durukan PB, Erdem HR, Yorgancioglu ZR. Grip strength: effect of hand dominance. Singapore medical journal. 2002 May 1;43(5):234-7. Google Scholar

25. Ertem K, Inan M, Yologlu S, Elmali N, Harma A, Sahin S, Bora A. Effects of dominance, body mass index and age on grip and pinch strength. Isokinetics and exercise science. 2003 Jan 1;11(4):219-23. https://doi.org/10.3233/IES-2003-0150

26. Özcan A, Tulum Z, Pınar L, Başkurt F. Comparison of pressure pain threshold, grip strength, dexterity and touch pressure of dominant and non-dominant hands within and between right-and left-handed subjects. Journal of Korean medical science. 2004 Dec 1;19(6):874-8. https://doi.org/10.3346/jkms.2004.19.6.874

27. Choi KH, Kim DM, Lee SY, Lee JH, Kong YK. Evaluation of the controlled grip force exertion tasks associated with age, gender, handedness and target force level. International Journal of Occupational Safety and Ergonomics. 2018 Oct 2;24(4):507-15. https://doi.org/10.1080/10803548.2017.1322832 